\title{
Expected effect of climate change on Sylt island: results from a multidisciplinary German project
}

\author{
Kai Ahrendt* \\ GEOMAR Research Center for Marine Geosciences, Wischhofstraße 1-3, 24148 Kiel, Germany
}

\begin{abstract}
Climate change (i.e. increasing mean sea level and storm activity) will influence the coastal development of sandy islands such as Sylt. To estimate the influence of climate change, a numerical model was used to predict the development of the coastline of Sylt island. Data for coastal retreat are available from 1876 to 1997 and were measured every $500 \mathrm{~m}$ longshore ( 70 profiles). Wave data are available from 1986 to 1997 . The model was calibrated and verified with these data. Coastal retreat was calculated to the year 2050 under the following scenarios (IPCC 1990): mean sea level $+25 \mathrm{~cm}$; tidal range $+25 \mathrm{~cm}$; wave height $+10 \%$; wave direction $\pm 10^{\circ}$. Little change in the configuration of the coastline of Sylt is expected over the next $50 \mathrm{yr}$ if the present strategy of western shore protection is maintained. No additional measures seem to be necessary. In contrast, if shore protection is not maintained, significant changes in coastline configuration (both west and east coasts) may occur, due in part to dramatic shore retreat by erosion, in the case of a $10 \%$ increase in wave height and a $10^{\circ}$ change in all westerly wind directions toward the north. Only moderate changes in coastline configuration and weak shore retreat through erosion can be expected if wind direction is turned $10^{\circ}$ to the south and wave height is maintained.
\end{abstract}

KEY WORDS: Climate change $\cdot$ Coastline development $\cdot$ Modelling

\section{INTRODUCTION}

Over the past 2 decades, public and scientific discussions have intensively stressed the consequences of anthropogenically induced global climate changes for coastal zones affected by human activities. From the human point of view it is most significant if changing climate has negative impacts on people living in areas directly affected by the consequences of climate change. In the case of global warming, near-coastal industrial zones and human settlements are endangered due to the assumed sea level rise and increased numbers of storm surges (e.g. von Storch et al. 1998). In order to optimise adaptation strategies regarding climate change and, furthermore, to develop and improve Integrated Coastal Zone Management (ICZM) tools, we need an inventory of regional environmental conditions as well as socio-economic and psychological aspects of affected societies.

*E-mail: kahrendt@geomar.de
The island of Sylt (Fig. 1) is one of the most prominent and famous sites in western Europe affected by coastal retreat. Sylt is situated on the west coast of Schleswig-Holstein, northern Germany, and is directly influenced by wave attack. Sylt is built up of PlioPleistocene outcrops in the middle of the island, between Kampen and the south of Westerland. The

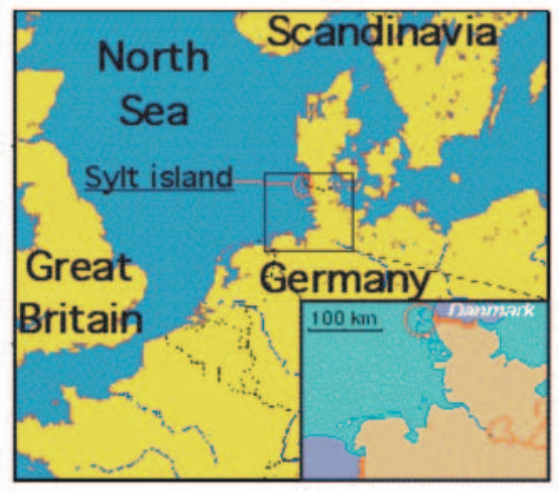

Fig. 1. Overview of study area 
North Sea reached these outcrops 7000 yr ago at a level $\sim 10 \mathrm{~m}$ below recent sea level. The mean coastal retreat during the last $7000 \mathrm{yr}$ has been estimated as $1.5 \mathrm{~m} \mathrm{yr}^{-1}$. Long spits developed from the outcrops to the north to List and to the south to Hörnum-Odde. Under the protection of these spits a landscape comparable to the modern Wadden Sea and a moory landscape developed. During the catastrophic storm surges in the Middle Ages Sylt become a real island. The first more or less realistic map is from 1650 (Fig. 2); the coastline of 1240 is more or less schematic.

The morphodynamic system of the west coast of Sylt island is characterised by a longshore bar and trough and ridge and runnel. Rip currents occur between 700 and $1400 \mathrm{~m}$ alongshore. The distance between the longshore bar and the beach is 200 to $400 \mathrm{~m}$. Tidal currents are dominant at $<10 \mathrm{~m}$ depth seaward of the longshore bar, with resulting sediment transport to the north (Ahrendt 1994). Complex sediment exchange takes place between the longshore bar and the beach, with resulting sediment loss northwards, north of Westerland and southwards, south of Westerland (Fig. 3).

The first georeferenced map is from the year 1870. The coastal retreat from 1870 to 1952 and from 1952 to 1984 is shown in Fig. 4. An increase in coastal retreat occurred from 1952 to 1984. However, the general coastline configuration could be maintained since the middle of the 1980s by sand replenishments. The sediment loss is $\sim 1.2 \times 10^{6} \mathrm{~m}^{3} \mathrm{yr}^{-1}$. Between the $10 \mathrm{~m}$ depth contour and the beach $0.8 \times 10^{6} \mathrm{~m}^{3} \mathrm{yr}^{-1}$ is lost; $0.4 \times 10^{6} \mathrm{~m}^{3} \mathrm{yr}^{-1}$ is lost by dune erosion. To the north, $0.8 \times 10^{6} \mathrm{~m}^{3} \mathrm{yr}^{-1}$ is lost and $0.4 \times 10^{6} \mathrm{~m}^{3} \mathrm{yr}^{-1}$ is lost to the south, calculated by depth of closure and map analysis (see Table 3 ).

Wave climate has been measured continuously since 1986 at $10 \mathrm{~m}$ depth (Table 1$)$. Westerly winds between $247.5^{\circ}$ and $315^{\circ}$ are dominant. The maximum wave height was $\sim 9 \mathrm{~m}$.

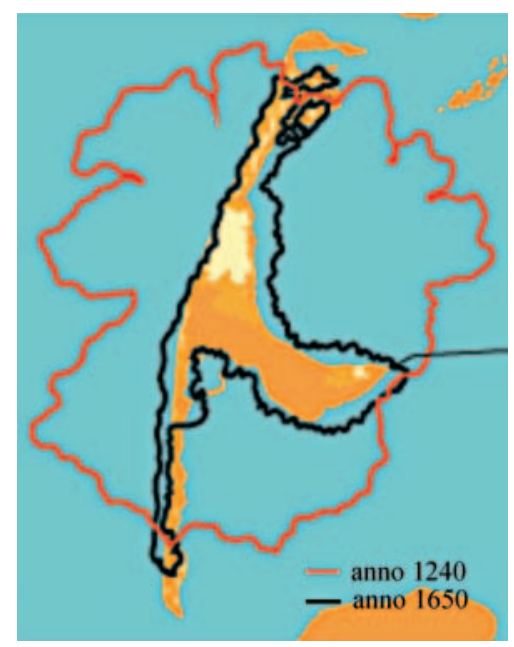

Fig. 2. The island of Sylt in 1240 and 1650

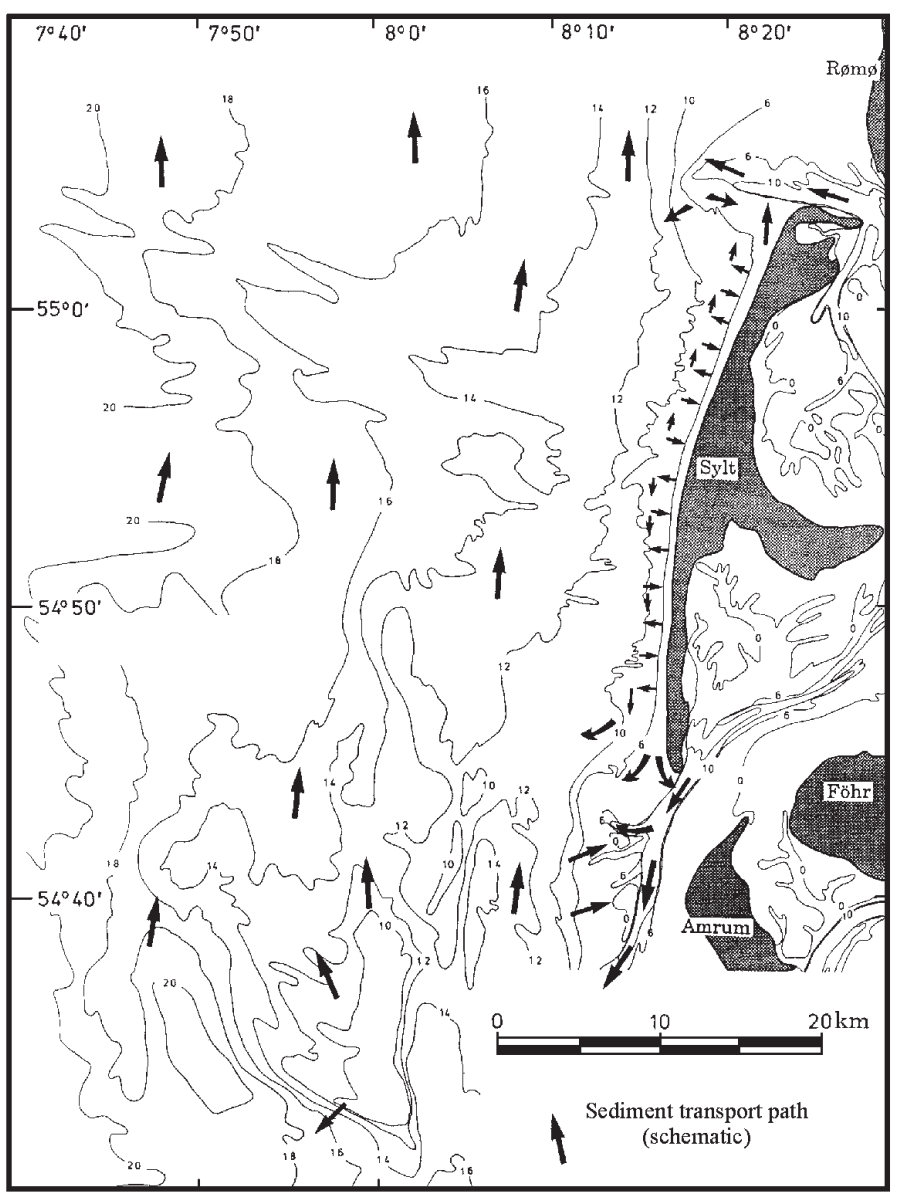

Fig. 3. Sediment transport around Sylt (schematic)

This vulnerable island has a multi-functional socioeconomic character (e.g. tourism) and is covered by a mixture of natural and cultural territories. Besides high standards in residential and recreation facilities, Sylt provides unique aspects of a biotope and offers excellent opportunities for the development and establishment of coastal protection techniques.

According to model predictions (IPCC 1990), a mean global sea level rise of $0.49 \mathrm{~m}$ by 2100 (considering local variations) will strongly affect the island of Sylt and the adjacent region. Today, little is known about regional climate change and potential consequences on environmental and socio-economic conditions. In order to improve our understanding of the relationship between humans and natural environment, and to develop ICZM as an integrative tool to be applied to natural and developed coastal systems on regional and local scales, the case study of Sylt was designed to incorporate 7 different disciplines: coastal and water engineering, ecology, economics, geography, geology, psychology and sociology. The focus of this paper is only future coastal development. For more details see: http://www.iczm.de/ 

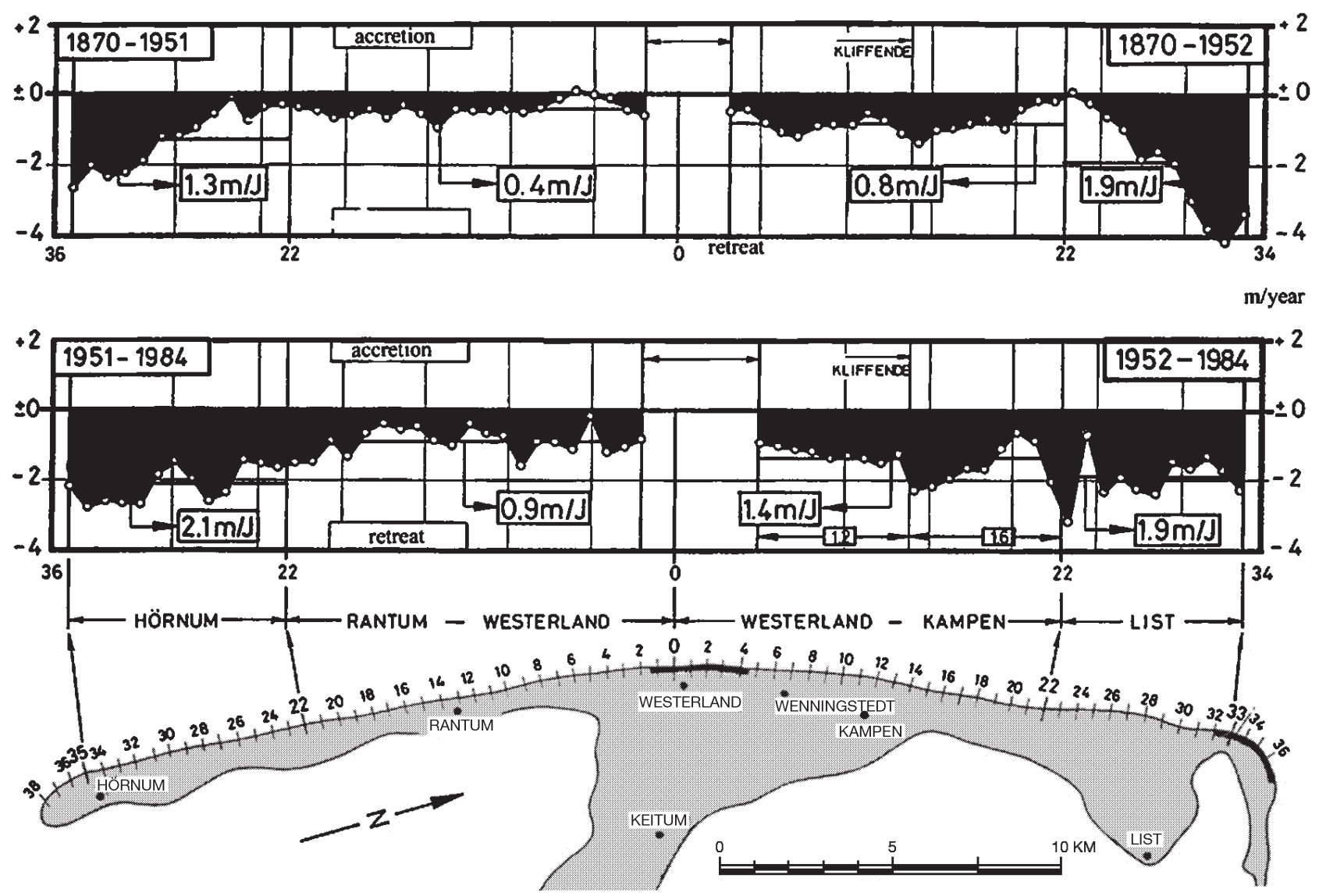

Fig. 4. Coastal retreat from 1872 to 1984 (after Amt für Ländliche Räume unpubl.)

Table 1. Wave statistics (\%) for the 4018 d from 1 Oct 1986 to 30 Sep 1997

\begin{tabular}{|c|c|c|c|c|c|c|c|c|c|c|c|c|c|c|c|c|c|}
\hline \multirow{2}{*}{$\begin{array}{l}H \\
(\mathrm{~m})\end{array}$} & \multicolumn{16}{|c|}{ Degree } & \multirow[t]{2}{*}{ Totals } \\
\hline & 0.0 & 22.5 & 45.0 & 67.5 & 90.0 & 112.5 & 135.0 & 157.5 & 180.0 & 202.5 & 225.0 & 247.5 & 270.0 & 292.5 & 315.0 & 337.5 & \\
\hline 0.25 & & & & & & & & & & & & & & & & & \\
\hline 0.50 & 1.650 & 1.305 & 1.019 & 0.587 & 0.342 & 0.302 & 0.295 & 0.250 & 0.516 & 0.843 & 1.209 & 1.533 & 2.658 & 4.233 & 6.568 & 1.724 & 25.035 \\
\hline 0.75 & 0.476 & 0.133 & 0.154 & 0.089 & 0.114 & 0.093 & 0.179 & 0.325 & 0.456 & 0.599 & 1.079 & 3.739 & 2.616 & 4.285 & 7.739 & 1.296 & 23.372 \\
\hline 1.00 & 0.107 & 0.002 & 0.011 & & 0.002 & 0.005 & 0.011 & 0.011 & 0.094 & 0.252 & 1.198 & 2.958 & 0.554 & 4.002 & 3.524 & 1.313 & 14.045 \\
\hline 1.25 & 0.064 & 0.000 & & & 0.001 & & 0.003 & 0.008 & 0.035 & 0.185 & 0.991 & 1.865 & 0.730 & 3.356 & 2.197 & 0.719 & 10.154 \\
\hline 1.50 & 0.064 & 0.002 & & & & & & & 0.002 & 0.081 & 0.639 & 1.251 & 0.760 & 2.414 & 1.556 & 0.412 & 7.181 \\
\hline 1.75 & 0.021 & & & & & & & & 0.001 & 0.042 & 0.473 & 0.937 & 0.764 & 1.829 & 1.150 & 0.232 & 5.450 \\
\hline 2.00 & 0.002 & & & & & & & & 0.001 & 0.040 & 0.324 & 0.672 & 0.678 & 1.514 & 0.870 & 0.105 & 4.206 \\
\hline 2.25 & & & & & & & & & 0.001 & 0.032 & 0.194 & 0.534 & 0.544 & 1.179 & 0.599 & 0.047 & 3.131 \\
\hline 2.50 & & & & & & & & & & 0.009 & 0.093 & 0.430 & 0.442 & 0.801 & 0.440 & 0.030 & 2.246 \\
\hline 2.75 & & & & & & & & & & & 0.085 & 0.239 & 0.422 & 0.593 & 0.311 & 0.003 & 1.653 \\
\hline 3.00 & & & & & & & & & & & 0.053 & 0.201 & 0.349 & 0.419 & 0.208 & 0.003 & 1.232 \\
\hline 3.25 & & & & & & & & & & & 0.024 & 0.170 & 0.271 & 0.264 & 0.078 & 0.003 & 0.809 \\
\hline 3.50 & & & & & & & & & & & 0.009 & 0.106 & 0.196 & 0.253 & 0.062 & & 0.627 \\
\hline 3.75 & & & & & & & & & & & 0.002 & 0.062 & 0.123 & 0.180 & 0.029 & & 0.397 \\
\hline 4.00 & & & & & & & & & & & 0.001 & 0.028 & 0.076 & 0.091 & 0.009 & & 0.205 \\
\hline 4.25 & & & & & & & & & & & & 0.011 & 0.045 & 0.058 & 0.001 & & 0.115 \\
\hline 4.50 & & & & & & & & & & & & 0.012 & 0.029 & 0.042 & & & 0.083 \\
\hline 4.75 & & & & & & & & & & & & 0.002 & 0.012 & 0.020 & & & 0.034 \\
\hline 5.00 & & & & & & & & & & & & 0.003 & 0.008 & 0.006 & & & 0.017 \\
\hline 5.25 & & & & & & & & & & & & 0.001 & 0.004 & & & & 0.005 \\
\hline Totals & 2.385 & 1.443 & 1.183 & 0.676 & 0.459 & 0.400 & 0.488 & 0.594 & 1.108 & 2.082 & 6.374 & 14.754 & 11.283 & 25.540 & 25.34 & 5.888 & 100.0 \\
\hline
\end{tabular}




\section{MODEL SCENARIOS AND RESULTS}

Numerical simulations of alongshore sediment transport and subsequent coastline development were carried out using the LITPACK model, supplied by the Danish Hydraulic Institute (see e.g. Engelund \& Fredsoe 1976). Some of the physical variables considered in the model are: (1) wave direction and height; (2) current conditions; (3) grain size distribution of local deposits; and (4) the declination of coast-normal and coast-parallel topographic profiles. Due to a significant lack of data and observations on local climatic changes, meteorological and oceanographic parameters were derived from IPCC simulations in order to initiate the LITPACK simulations (Table 2).

Moreover, the simulations are supported by findings about past changes in coastal morphology due to geological, geomorphological, meteorological, hydrological and socio-economical processes. The model results will be used as database for project partners with social and economic perspectives (i.e. human activities, settlement, damage costs etc.).

The sediment drift was calculated by a model which consists of 2 calculation parts: a longshore current calculation and a sediment transport calculation (STP). The cross-shore distribution of longshore current, wave height and set-up for an arbitary coastal profile, is found by solving the long- and cross-shore momentum balance equations. The longshore current model includes a description for regular and irregular waves, the influences of tidal current, wind stress and non-uniform bottom friction as well as wave refraction, shoaling and breaking. The associated sediment transport is based on the local wave, current and sediment conditions. The model is an intra-wave-period model which describes the time-varying distribution of suspended load and bed load within the wave period in combined wave and current motion, including the effect of wave breaking when relevant. STP is described by:

$$
\theta=\frac{u}{(s-1) g d} \Rightarrow q_{\mathrm{B}}=\frac{1}{T} \int_{0}^{\mathrm{T}} f(\theta) \mathrm{d} t
$$

where, $\theta=$ Shields' parameter; $u=$ boundary layer velocity; $s=$ relative density of bed material; $g=$ acceleration due to gravity; $d=$ grain size; $q_{\mathrm{B}}=$ bed load transport $T=$ wave period
The suspended load is described by the sediment concentration $C$ :

$$
\frac{\partial C}{\partial t}=\frac{\partial}{\partial z}\left[\varepsilon_{\mathrm{s}} \frac{\partial C}{\partial z}\right]+w \frac{\partial C}{\partial z}
$$

where $C=$ sediment concentration; $z=$ vertical dimension (zero at bed); $\varepsilon_{\mathrm{s}}=$ eddy viscosity; $W=$ settling velocity.

The concentration near the bed $C_{\mathrm{B}}$ is given at $z=2 d$. $C_{\mathrm{B}}$ is determined after Bagnold (1954) as a function of $\theta$. The suspended load $q_{\mathrm{s}}$ is calculated as the product of sediment concentration $C_{1}$ current velocity $U$ and the mean value of the wave period $T$ :

$$
q_{\mathrm{s}}=\frac{1}{T} \int_{0}^{T} \int_{2 d}^{D} C U \mathrm{~d} y \mathrm{~d} t
$$

where $D=$ depth

LITDRIFT describes the longshore current and the sediment transport. The sediment transport is calculated by STP based on local wave, current and sediment conditions (Fredsoe 1984, Deigaard et al. 1988):

$$
\tau_{\mathrm{b}}-\frac{\mathrm{d}}{\mathrm{d} y}\left[\rho \mathrm{E} D \frac{\mathrm{d} u}{\mathrm{~d} y}\right]=-\frac{\mathrm{d} s_{\mathrm{xy}}}{\mathrm{dy}}+\tau_{\mathrm{w}}+\tau_{\mathrm{cur}}
$$

where $\tau_{\mathrm{b}}=$ bed shear stress by surf current; $\tau_{\mathrm{w}}=$ shear stress by wind; $\tau_{\text {cur }}=$ shear stress by current; $\rho=$ density of sea water; $\mathrm{E}=$ impulse coefficient; $D=$ depth; $S_{\mathrm{xy}}=$ coastal parallel radiation stress.

As a result, LITDRIFT is able to give a deterministic description of the cross-shore distribution of longshore sediment transport for an arbitrary, non-uniform bathymetric and sediment profile, as well as a detailed description of the sediment budget.

LITLINE calculates the longshore coastline position based on input of wave climate as a time series. The model is based on a ' 1 line theory', in which the crossshore profile is assumed to remain unchanged during erosion/accretion. Coastal morphology is solely described by the coastline position (cross-shore direction) and the coastal profile at a given longshore position. The programme calculates and tabulates transport rates as a function of water level, the surface slope due to regional currents, grain size, wave period, height and angle compared to the coastline normal:

$$
\theta=\frac{\partial y_{\mathrm{c}}(x)}{\partial t}=-\frac{1}{h_{\mathrm{act}}(x)} \frac{\partial Q(x)}{\partial x}+\frac{Q_{\text {sou }}(x)}{h_{\mathrm{act}}(x) \Delta x}
$$

Table 2. Description of the scenarios

\begin{tabular}{|lccc|}
\hline Scenario & Wave height & Wave direction & Change in water level \\
\hline A & $10 \%$ increase of wave height in westerly directions & - & $0.00-0.50 \mathrm{~m}$ \\
B & - & $10^{\circ}$ to north & $0.00-0.50 \mathrm{~m}$ \\
C & - & $10^{\circ}$ to south & $0.00-0.50 \mathrm{~m}$ \\
D & $10 \%$ increase of wave height in westerly direction & $10^{\circ}$ to north & $0.00-0.50 \mathrm{~m}$ \\
E & $10 \%$ increase of wave height in westerly direction & $10^{\circ}$ to south & $0.00-0.50 \mathrm{~m}$ \\
\hline
\end{tabular}


where $y_{c}(x)=$ distance from the baseline to the coastline; $t=$ time; $Q(x)=$ long-shore transport of sediment, expressed in volume; $x=$ long shore position; $\Delta x=$ longshore discretization step; $Q_{\text {sou }}(x)=$ source/sink term expressed in volume per $\Delta \mathrm{x}_{i} h_{\mathrm{act}}(\mathrm{x})=$ height of active cross-shore profile. The variables $h_{\text {act }}(x)$ and $Q_{\text {sou }}(x)$ are calculated based on user specifications, while the longshore transport rate $Q(x)$ is determined from tables relating the transport rate to hydrodynamic conditions at the point of wave breaking. For more details see Deigaard et al. (1988) and Foster \& Skou (1992).

The actual sediment loss was calculated as $1.2 \times$ $10^{6} \mathrm{~m}^{3} \mathrm{yr}^{-1}$ (Table 3$)$. This is approximately the same as estimated by map analysis. When the wave climate is changed $10^{\circ}$ to the north, the sediment loss is nearly the same but the direction is opposite. This would result in an increasing coastal retreat north of Westerland. When the wave climate is changed $10^{\circ}$ to the south, the sediment transport is also nearly the same but without a net transport to the south. This would result in a coastal retreat south of Westerland. An increase in the wave height of $10 \%$ will also result in an increase in the sediment transport, from 1.2 to 1.95 $\times 10^{6} \mathrm{~m}^{3} \mathrm{yr}^{-1}$. A rise in sea level of $25 \mathrm{~cm}$ or $50 \mathrm{~cm}$ does not result in a significant increase in sediment transport but it causes the main sediment transport region to shift shoreward.

The coastal retreat has been measured since 1870 by profiles every $500 \mathrm{~m}$ along the coastline. A $120 \mathrm{yr}$ time series from 1872 to 1992 was used for calibrating the LITLINE model. An example for calibration of the measured and calculated coastal retreat north of Westerland is shown in Fig. 5. This calibration was also done with the same quality for the southern part of Sylt.

The scenario-supported modeling efforts concerning the modern and future sediment budget on the western coast of Sylt identify the regions List, Kampen, Wenningstedt, Hörnum and Rantum as the areas of most concern. The minimum coastal retreat is shown in Fig. 6 and the maximum coastal retreat in 2050 (without coastal protection) is shown in Fig. 7. Investigations of the impact of sea level rise on sediment transport capacities do not generally show significant changes in resulting sediment transport. However, significant changes within individual profiles are evident. An increase of local sediment transport by a factor of 1 to 1.5 (with increasing wave height) within the next $50 \mathrm{yr}$ seems to be possible. Based on available techniques in coastal protection the forecasted long-term morphological development of Sylt seems to be controllable.
Table 3. Sediment losses in $10^{6} \mathrm{~m}^{3} \mathrm{yr}^{-1} . H_{\mathrm{s}}$ : significant wave height; negative values are losses to the south

\begin{tabular}{|lrrc|}
\hline & North & South & Total \\
\hline Sediment loss today & 850000 & -350000 & 1200000 \\
Wave climate change & & & \\
$10^{\circ}$ north, Scenario B & 195000 & -705000 & 1050000 \\
$10^{\circ}$ south, Scenario C & 1430000 & 45000 & 1475000 \\
$+10 \% H_{\mathrm{s}}$, Scenario A & 1480000 & -470000 & 1950000 \\
$+10 \% H_{\mathrm{s}}$ and & & & \\
$10^{\circ}$ north, Scenario D & 370000 & -1000000 & 1370000 \\
$+10 \% H_{\mathrm{s}}$ and & & & \\
$10^{\circ}$ south, Scenario E & 2450000 & 80000 & 2530000 \\
& & & \\
\hline
\end{tabular}

The general opinion of Sylt inhabitants is to not only care intensively about coastal protection of the island, but also to promote the development of future tourism and to improve job perspectives, particularly for young persons. However, only minor structural improvements were proposed by the Sylt authorities. Potential conflicts may arise from the ambivalent public position concerning tourism. On the one hand, the marketing sector propagates positive environmental factors such as surf, dunes and a $40 \mathrm{~km}$ sand beach to promote the public image of Sylt and, thereby, to enhance the touristic usage of the island or, at least, maintaining the current level. On the other hand, the modern capacity of tourism or even an increase in touristic activities are regarded as a reduction in the quality of life and a danger to the internal functions of the community.

The project efforts show that it is necessary to investigate a changing environment like Sylt from multidisciplinary perspectives. According to our numerical simulations, climate change may strongly promote Sylt's future shore retreat subsequent to enhanced storm and wave activity, if modern strategies of shore protection are not maintained. In this case, a dramatically changing and retreating coastline would have substantial impacts on human activities, quality of life

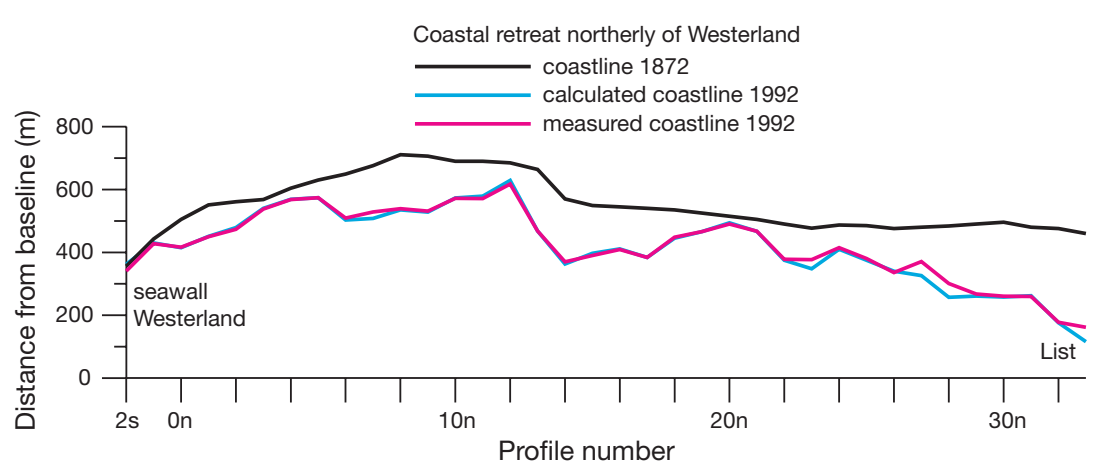

Fig. 5. Calibration of the model for the part north of Westerland 


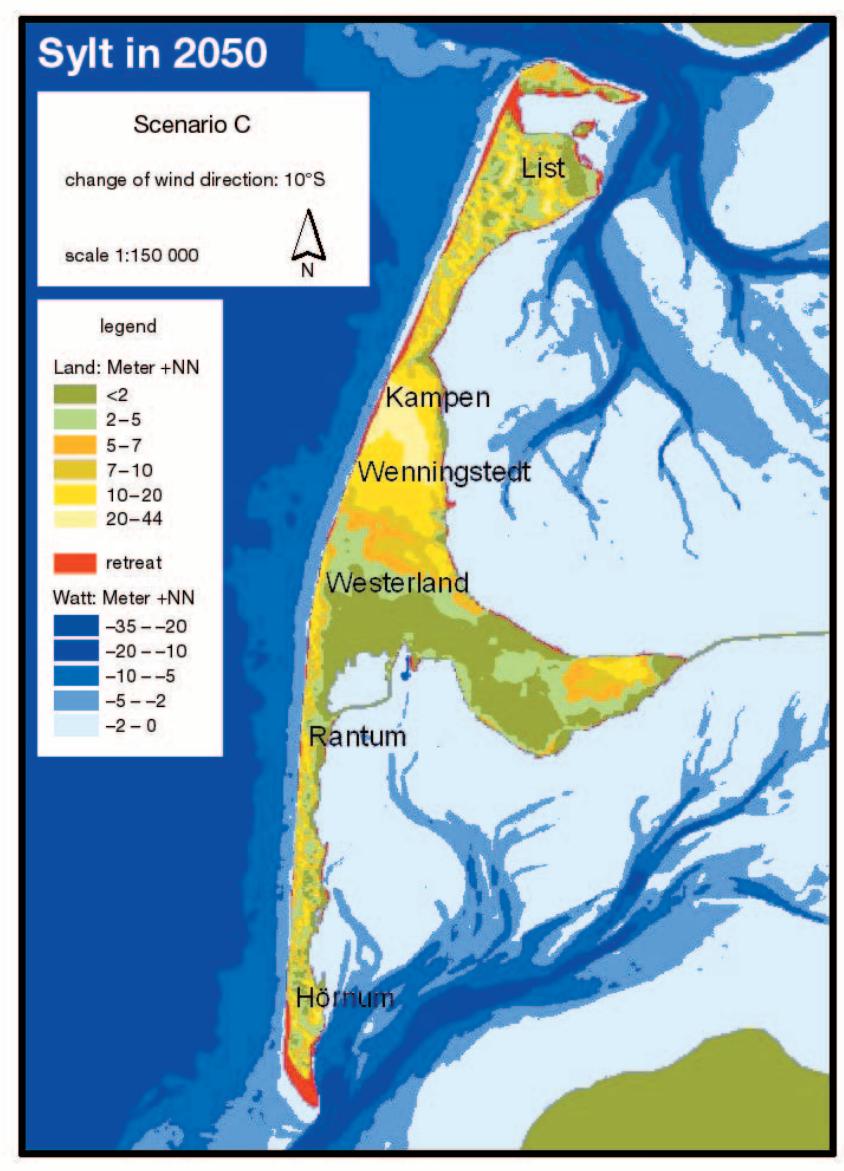

Fig. 6. Coastal retreat in 2050, changing wave direction $10^{\circ}$ to south

and economic potential on the island. However, with modern techniques in coastal protection and assuming only moderately increasing costs for beach replenishment, most of the sub-projects agree that the environmental and socio-economic consequences of potential climate change will be not be serious and will therefore be controllable for Sylt. Looking forward, it can be stated that recurrent coastal protection is an essential tool to reduce future changes in the coastline configuration of Sylt and to maintain the island as a unique biotope and a place with high quality of life. Furthermore, intensified future application of ICZM (Integrated Coastal Zone Management) with regard to the connections between human activities and natural processes in the north German Wadden Sea will help us to learn more about a fast changing environment and may reduce the costs of environmental damage.

Acknowledgements. The study was financially supported by the Bundesminister für Bildung und Forschung, Federal Republic of Germany (grant no. 01LK9526). The author is also indebted to the German Aerospace Centre (DLR).

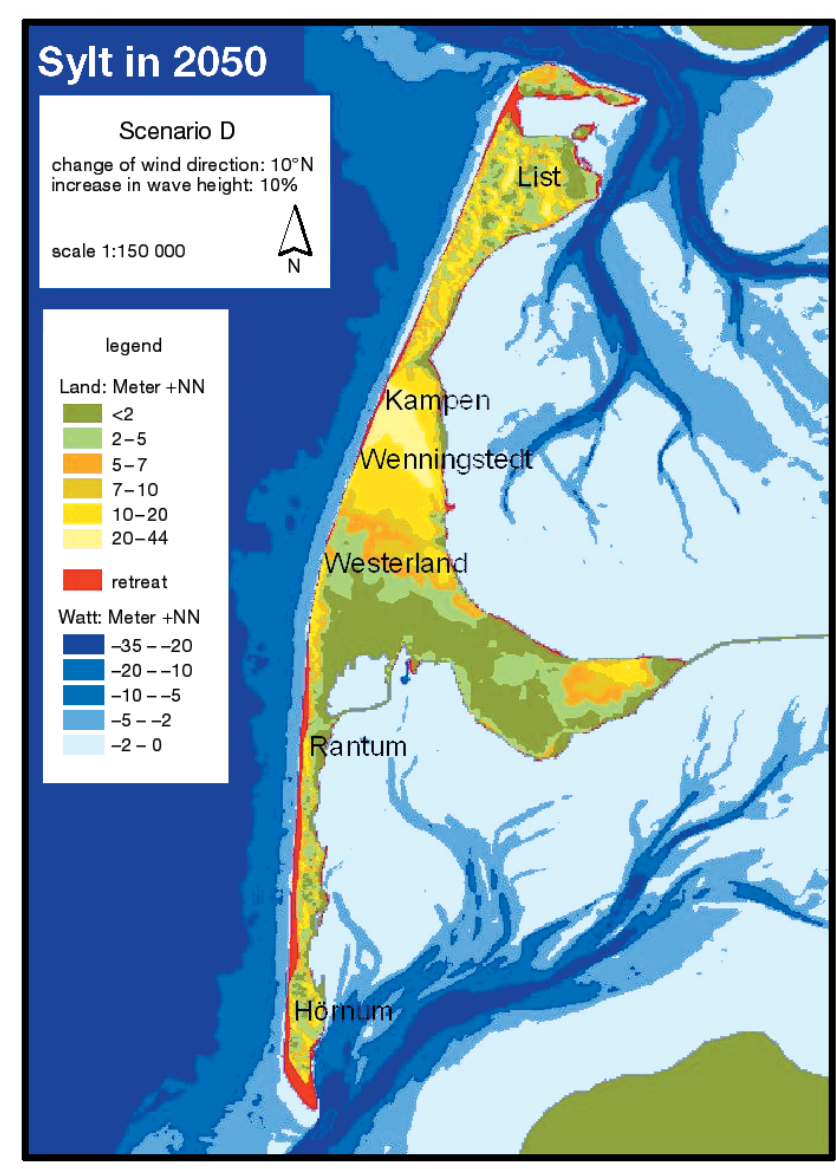

Fig. 7. Coastal retreat in 2050, changing wave direction $10^{\circ}$ to north and increasing wave height by $10 \%$

\section{LITERATURE CITED}

Ahrendt K (1994) Geologie und Küstenschutz am Beispiel Sylt/Deutsche Bucht. Ber For u Techn.zent Westküste 4, Forschungs- und Technologiezentrum Westküste, Büsum Bagnold RA (1954) Experiments on a gravity-free dispersion of large solid spheres in a Newtonian fluid under shear. Proc R Soc Lond A 225:49-63

Deigaard R, Fredsoe J, Hedegaard BI, Zyserman JA, Anderson $\mathrm{OH}$ (1988) Littoral drift model for nature environments. Proceedings of the 21st Coastal Engineering Conference, ASCE, New York, p 1603-1617

Engelund F, Fredsoe J (1976) A sediment transport model for straight alluvial channels. Nordic Hydrology 7:296-306

Foster T, Skou AJ (1992) LITPACK in integrated modelling system for littoral processes and coastline kinematics. 3rd International Software Exhibition for Environment Science \& Engineering, Como, Italy

Fredsoe J (1984) The turbulent boundary layer in combined wave-current motion. J Hydr Eng ASCE 100 (HY8): $1103-1120$

IPCC (1990) Climate change-the IPCC science assessment. Cambridge University Press, Cambridge

von Storch H, Langenberg H, Pohlmann T (1998) Stürme Seegang und Sturmfluten im Nordostatlantik. In: Lozán JL, Graßl H, Hupfer P (eds) Warnsignale Klima. Wissenschaftliche Auswertungen, Hamburg 